\title{
Cytoplasmic Body Myopathy with Hypertrophic Cardiomyopathy
}

\author{
Yoshiki Sekijima, Shu-ichi Ikeda, Satoshi Katai, Masayuki Matsuda, Takao Hashimoto, \\ Sei-ichi Haruta, Mafumi Owa, Toshihiko SaKaI*, Shin'ichi Takeda** and Nobuo Yanagisawa
}

A patient with cytoplasmic body myopathy presented muscle hypotonia from birth and developed progressive muscular atrophy and weakness, scoliosis, contracture of joints and cardiorespiratory failure. At the age of 17 , he died of heart failure. Post mortem examination revealed severe hypertrophy of cardiac walls and generalized muscular atrophy. Microscopic examination showed many cytoplasmic bodies in skeletal muscle fibers and myofiber disarray in myocardium. No cases of cytoplasmic body myopathy with hypertrophic cardiomyopathy have been reported previously. It is suggested that the $\mathrm{Z}$-line component is related to the formation of the cytoplasmic body in skeletal muscle and disarray in the cardiac muscle.

(Internal Medicine 34: 166-170, 1995)

Key words: congenital myopathy, contractile protein, Z-line component

\section{Introduction}

Cytoplasmic body myopathy is one of the very rare congenital myopathies which is characterized by many cytoplasmic bodies in skeletal muscle fibers (1-14). Clinically, cytoplasmic body myopathy reveals rather heterogeneous pictures as to heredity, age of onset, clinical symptoms and prognosis $(8,11)$. Only seven cytoplasmic body myopathy patients with cardiac disorders have been reported in the literature $(2,5,7-9)$, and no cytoplasmic body myopathy patient with hypertrophic cardiomyopathy (HCM) has ever been documented. Here, we report a cytoplasmic body myopathy patient with severe muscular atrophy, scoliosis, joint contracture and HCM, and discuss the relation between cytoplasmic bodies in skeletal muscles and myofiber disarray in the cardiac muscle.

\section{Case Report}

The patient is a 17-year-old Japanese boy. An aunt of his father suddenly died of unknown cause at the age of 60 and a cousin of his father had idiopathic scoliosis, but there was no family history of neuromuscular disorders nor consanguinity. He was the product of a full-term pregnancy with normal delivery. However, he presented mild muscular hypotonia since birth and, subsequently, delayed motor developmental milestones with progressive muscle wasting and weakness were noted. Scoliosis and contracture of joints appeared when he was 4 years old. He suffered from dyspnea on exercise and palpitation from the age of 12 and was admitted to our hospital at the age of 17 .

On admission, his body weight was $33 \mathrm{~kg}$ and his height was $138 \mathrm{~cm}$. The pulse was irregular at $100 / \mathrm{min}$ and his blood pressure was $110 / 70 \mathrm{mmHg}$. He was an intelligent boy. Cyanosis, jugular vein enlargement and generalized edema were found. Severe scoliosis, deformity of thorax, and contracture of limb joints were seen, and generalized muscular atrophy and weakness were observed (Fig. 1). Deep tendon reflexes were decreased in all limbs, and sensory disturbance or any symptoms suggestive of central nervous system involvement were lacking.

Routine blood studies showed the following abnormalities: GOT 61 IU/L (normal, 12-37), LDH 293 IU/L (114-220), $\gamma$ GTP $131 \mathrm{IU} / \mathrm{L}$ (8-50), CK $469 \mathrm{IU} / \mathrm{L}$ (43-272), aldolase $7.7 \mathrm{IU} /$ $\mathrm{L}$ (0.5-3.1). Arterial blood gas analysis at resting state showed severe hypoxia and hypercapnia $\left(\mathrm{pH} 7.374, \mathrm{PCO}_{2} 71.7 \mathrm{mmHg}\right.$, $\mathrm{PO}_{2} 30.9 \mathrm{mmHg}, \mathrm{SaO}_{2} 57.4 \%$ ). Cardiomegaly (cardiothoracic ratio $82.4 \%$ ) with pulmonary congestion was seen on a chest roentgenogram. Pulmonary function tests revealed restrictive ventilatory insufficiency [forced vital capacity (FVC) $500 \mathrm{ml}$, $\%$ FVC $15.8 \%]$. Electromyography showed polyphasic potentials

From the Third Department of Internal Medicine, Shinshu University School of Medicine, Matsumoto, *the Second Department of Pathology, Shinshu University School of Medicine, Matsumoto and **National Institute of Neuroloscience, NCNP, Tokyo

Received for publication February 7, 1994; Accepted for publication October 24, 1994

Reprint requests should be addressed to Dr. Yoshiki Sekijima, the Third Department of Internal Medicine, Shinshu University School of Medicine, Asahi 3-1-1, Matsumoto 390 


\section{CBM with HCM}
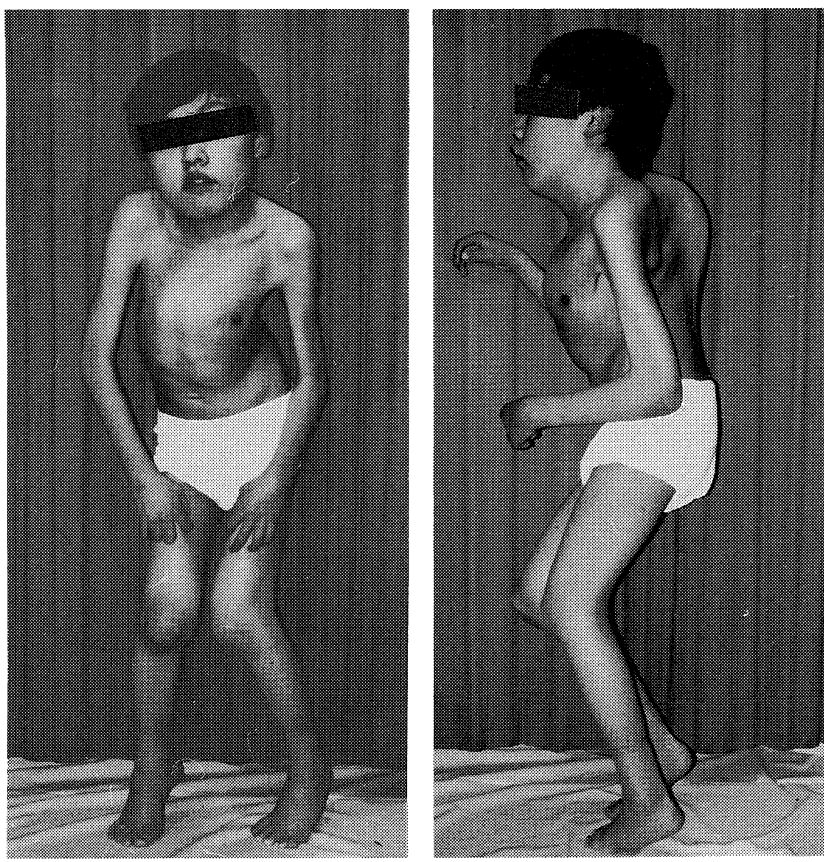

Fig. 1. General appearance at the time of admission (17 years old). Severe muscle atrophy, deformity of thorax and scoliosis are observed.

of small amplitude but no myogenic pattern.

Electrocardiogram (ECG) revealed sinus tachycardia, left axis deviation, first degree atrioventricular block, incomplete right bundle branch block, right atrial enlargement and right ventricular hypertrophy. Holter ECG showed frequent premature ventricular contraction, premature supraventricular contraction, and paroxysmal supraventricular tachycardia. Echocardiography disclosed slight pericardial effusion, marked enlargement of both atriums, and hypertrophy of both ventricular walls. Doppler echocardiography showed a slight tricuspid regurgitation. Cardiac catheterization revealed severe pulmonary hypertension and both ventricular filling pressures were elevated (Table 1). Three months later, he died of heart failure.

\section{Autopsy findings}

At autopsy, there were no remarkable pathologic changes

Table 1. Cardiac Catheterization Data of This Patient

\begin{tabular}{ll}
\hline & Catheterization data \\
\hline$\overline{\mathrm{RA}}$ & $24 \mathrm{mmHg}$ \\
$\mathrm{RV}$ & $63 / \mathrm{EDP} 28 \mathrm{mmHg}$ \\
$\mathrm{PA}$ & $74 / 48(54) \mathrm{mmHg}$ \\
$\overline{\mathrm{PCW}}$ & $27 \mathrm{mmHg}$ \\
\hline $\mathrm{CO}$ & $2.51 \mathrm{~L} / \mathrm{min}$ \\
$\mathrm{CI}$ & $2.49 \mathrm{~L} / \mathrm{min} / \mathrm{m}^{2}$
\end{tabular}

$\overline{\mathrm{RA}}$ : mean right atrial pressure, $\mathrm{RV}$ : right ventricular pressure, $\mathrm{PA}$ : pulmonary artery pressure, $\overline{\mathrm{PCW}}$ : mean pulmonary capillary wedge pressure, $\mathrm{CO}$ : cardiac output, CI: cardiac index. except for the skeletal muscles and heart. Frozen sections of 8 $\mu \mathrm{m}$ thickness were prepared from diaphragm, biceps brachii, quadriceps femoris, iliopsoas and paravertebral muscles. All muscle specimens showed mild variation in fiber size, increase of internal nuclei and many vacuoles. The most notable feature was the presence of intracytoplasmic inclusions in some degenerated muscle fibers: these cytoplasmic bodies were round or oval, and appeared reddish with HE stain (Fig. 2A) and purplish with modified Gomori-Trichrome stain (Fig. 2B), but did not show any histochemical reactivities for either NADHtetrazolium reductase or routine ATPase at $\mathrm{pH}$ 9.4. Dystrophin immunostaining was performed using 1:500 mouse monoclonal antibody 4C5 raised against a C-terminal peptide of dystrophin (15), revealing the normal localization of this protein in the muscle fibers examined. Formalin-fixed muscle tissues were post-fixed with $1 \%$ osmium teroxide, embedded in epoxy risin, and used for conventional electron microscopic observations. The core of the cytoplasmic bodies showed a fine filamentous appearance intermixed with dense amorphous material and the electron density of these bodies closely resemled that of Z-line (Fig. 3A). Moreover, some cytoplasmic bodies contained structures similar to deformed Z-lines (Fig. 3B) and the periphery of
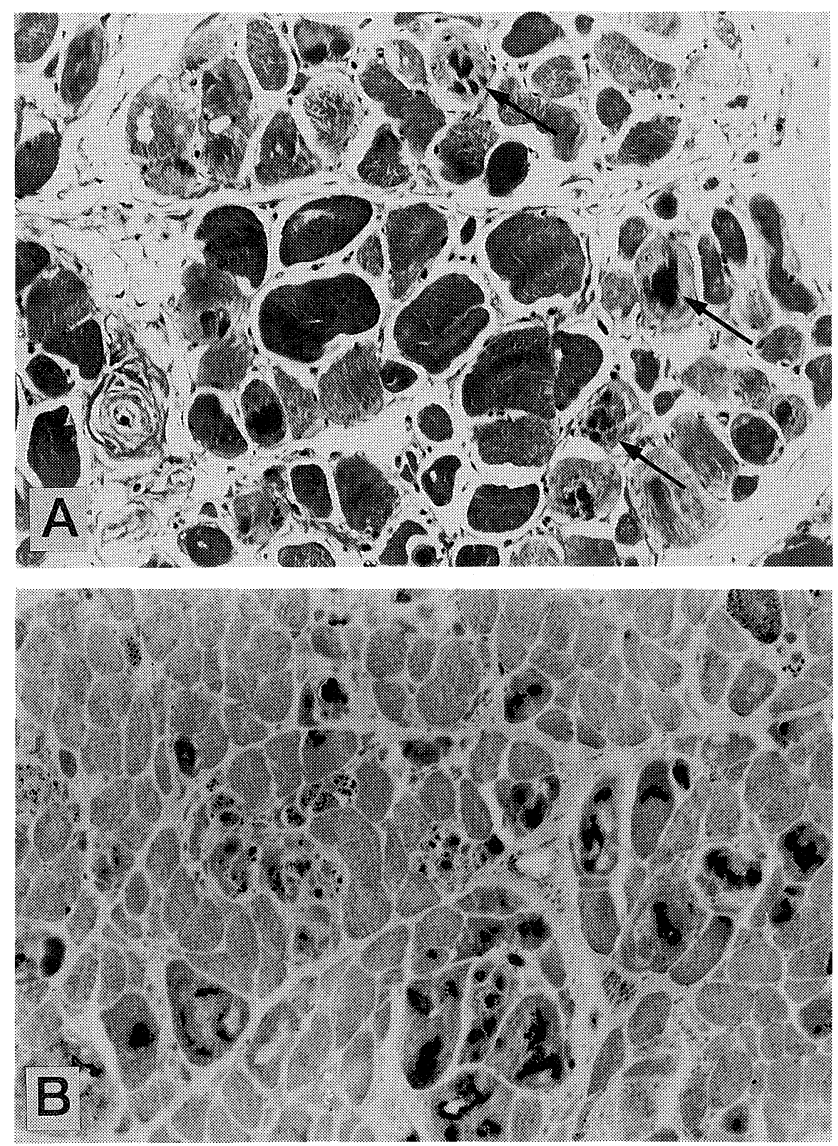

Fig. 2. Representative histological findings of muscles. A) Diaphragm, HE stain, $\times 150$. B) Right biceps brachii, Modified Gomori-trichrome stain, $\times 100$. Many cytoplasmic bodies are visible in muscle fibers. Arrows indicate typical cytoplasmic bodies in muscle fibers. 

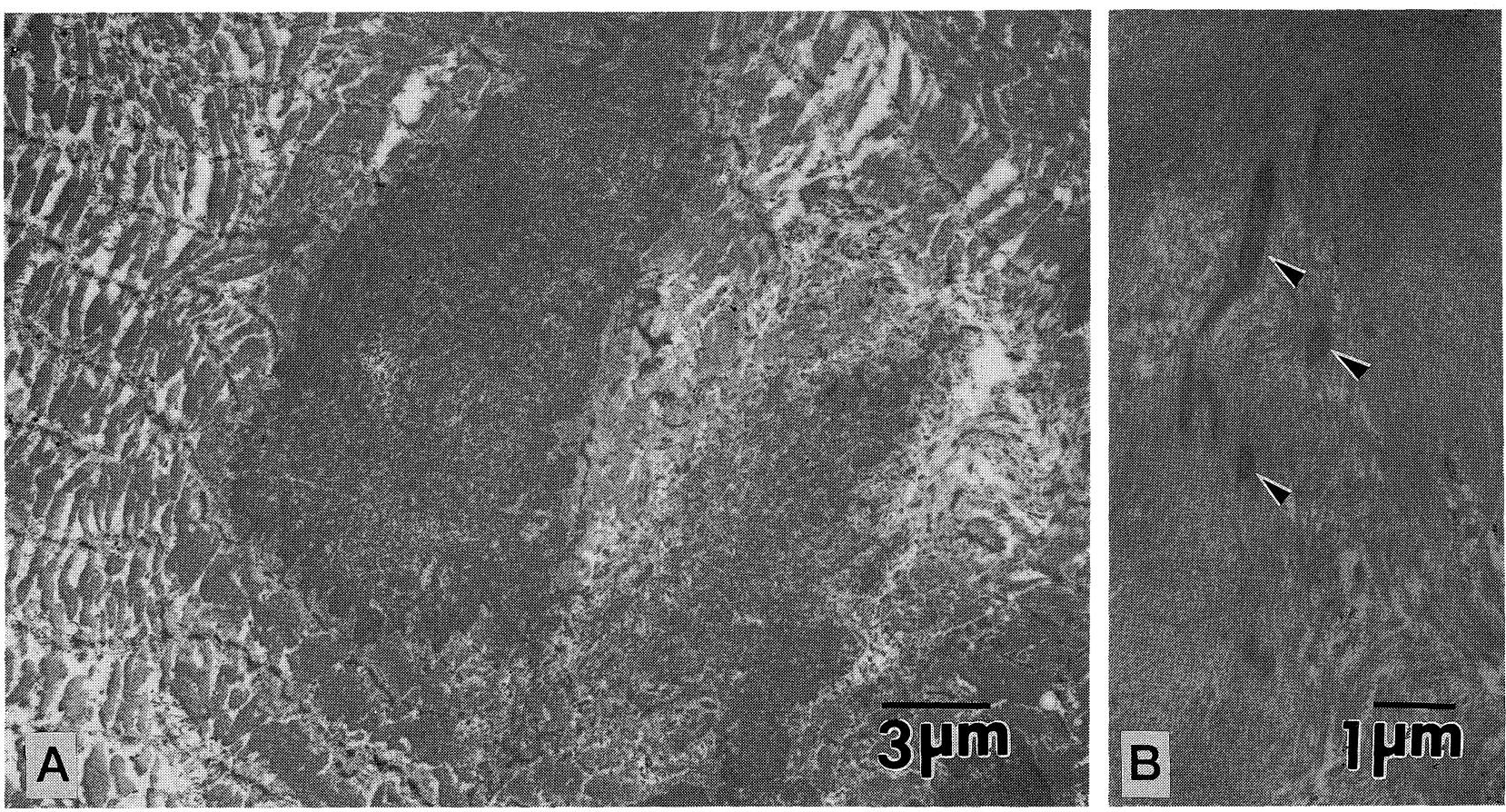

Fig. 3. A) Electronmicrophotograph of cytoplasmic bodies in the muscle fiber of diaphragm. Dense filamentous cores are seen in a degenerating muscle fiber. B) A cytoplasmic body under high magnification. Arrowheads indicate electron dense structures which are morphologically different from nemaline rods.
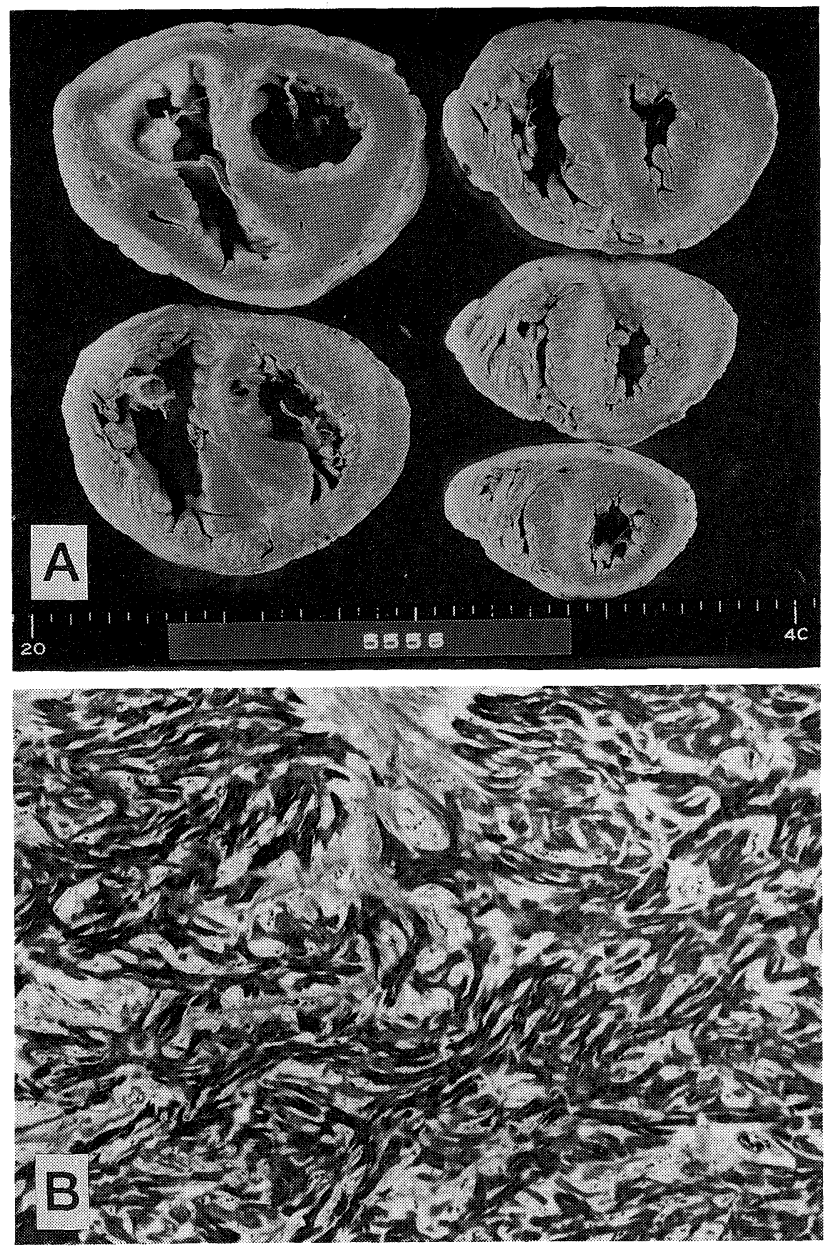

these bodies seemed to be continuous with distorted myofibrils.

The heart weighed $350 \mathrm{~g}$ and showed marked hypertrophy of both ventricular walls (right ventricular wall, $7 \mathrm{~mm}$; left ventricular wall, $17 \mathrm{~mm}$ ) (Fig. 4A), which is typical of hypertrophic cardiomyopathy. On microscopic examination, a small number of myocardial cells revealed degenerative changes and myofiber disarray was seen in almost all areas of the myocardium (Fig. 4B). Scattered slight fibrosis with fatty infiltration was also observed, especially in the subendocardial conduction system. However, there were neither cytoplasmic bodies nor abnormal intracytoplasmic deposits in the cardiac muscle fibers and the intramural vessels revealed no significant changes. Concerning the pathology of lungs, extensive congestion was observed, but there was no fibrosis.

\section{Discussion}

Cytoplasmic bodies are unique sarcoplasmic inclusions of the skeletal muscle fibers (16), which can be found in various neuromuscular disorders, including inflammatory myopathy, myotonic dystrophy, progressive muscular dystrophy, periodic paralysis and mitochondrial myopathies (17). The term cytoplasmic body myopathy has been applied when many muscle fibers contain cytoplasmic bodies but no other definitive diag-

Fig. 4. A) Cross-sections of both ventricles. Marked hypertrophy of both ventricular wall are observed. B) Histological findings of the left ventricular wall. Myofiber disarray with slight interstitial fibrosis is seen (Azan-Mallory stain, $\times 150$ ). 
nosis could be made (8). Twenty-five patients of cytoplasmic body myopathy have been reported in the literature (1-14), but the clinical pictures of cytoplasmic body myopathy vary as to heredity, onset, clinical symptoms and prognosis $(8,11)$. This disorder, therefore, seems to encompass several different etiologies.

Chou and Mizuno reported that experimentally, spheroid cytoplasmic bodies are induced by local tetanus in rat plantaris muscle and these spheroid cytoplasmic bodies stain positively for desmin and actin immunohistochemically (18). Other studies revealed that cytoplasmic bodies in cytoplasmic body myopathy also stain positively for desmin (19), actin (14) and $\alpha$ actinin, which are all contractile proteins known to be linked at the level of the Z-line. On electron mciroscopy, MacDonald and Engel reported that cytoplasmic bodies appear to originate from the Z-line, because they are located in the same plane as the Zline, and their dense cores appear continuous with the Z-line (17).

Cytoplasmic body myopathy with cardiac dysfunctions has been reported in only seven patients $(2,5,7-9)$ (Table 2). Almost all the patients of cytoplasmic body myopathy with cardiopathy presented a progressive muscular atrophy and poor prognosis, as in the present patient, but the details of the cardiac disorders were not described. Clinical symptoms of heart failure and abnormalities of ECG or echocardiography in these patients do not necessarily indicate primary disturbance of cardiac muscle, since severe weaknss of respiratory muscles and/or marked deformity of the thorax also cause congestive heart failure. In the present patient, marked hypertrophy of both ventricular walls on echocardiography, diastolic dysfunction in cardiac catheterization, and myofiber disarray of myocardium on light microscopic examination support primary disturbance of cardiac muscle, that is, HCM.
It is intriguing in this patient that cytoplasmic bodies in skeletal muscles and HCM in cardiac muscle coexisted. These findings suggest that an abnormality of some muscle components which is expressed both in skeletal muscle and cardiac muscle might be the basic defect in this patient. The molecular genetic background of cytoplasmic body myopathy remained unidentified while data on the molecular genetics of familial hypertrophic cardiomyopathy (FHC) are accumulating. FHC, which is transmitted as an autosomal dominant trait, is a major cause of sudden death in the young. The locus of genetic abnormality in this disease was first mapped to chromosome 14q11-q12 (20) and revealed that the faulty gene codes for $B$ myosin heavy chain, one of the major contractile proteins of the human cardiac muscle and slow skeletal muscle fibers (21). Subsequent studies revealed that mutations in the $\alpha$-tropomyosin gene and cardiac troponin $\mathrm{T}$ gene cause FHC linked to chromosome $15 \mathrm{q} 2$ and chromosome $1 \mathrm{q} 3$ (22-24). Other loci were mapped to chromosome 11 (25), 18q (26), 16 (27) and 2q (28). It is not known what these genes code for. However, it is suggested that they encode other contractile proteins, which are expressed mainly in the cardiac muscle ( $\alpha$ myosin heavy chain, cardiac myosin light chain 1 and 2, cardiac $\alpha$ actin, cardiac troponin C, I and others). Each of these protein isoforms has a role in the structure or contractile function of cardiac muscle.

We do not know the molecular basis of HCM in this case, although there is a possibility that an abnormality of a musclespecific gene caused the cytoplasmic bodies in the skeletal muscle and the disarray of cardiac muscle fibers. A defect in a gene-coding for $\alpha$ Z-line component could cause an abnormality in the muscle cell structure. Indeed, over-expression of truncated $\alpha$-actinin formed a hypertrophied Z-line and nemalinelike bodies in cultured myotubes (29). In the present patient, it

Table 2. Summarized Clinical Pictures of Patients with Cytoplasmic Body Myopathy Showing Cardiac Disorders

\begin{tabular}{|c|c|c|c|c|c|c|c|c|}
\hline & $\begin{array}{c}\text { Kinoshita (2) } \\
\text { et al }\end{array}$ & \multicolumn{3}{|c|}{ Edström et al (5) } & $\begin{array}{c}\text { Wolburg (7) } \\
\text { et al }\end{array}$ & $\begin{array}{c}\text { Patel (8) } \\
\text { et al }\end{array}$ & $\begin{array}{c}\text { Otsuji (9) } \\
\text { et al }\end{array}$ & $\begin{array}{c}\text { Present } \\
\text { case }\end{array}$ \\
\hline Sex & Female & Female & Male & Male & Male & Female & Male & Male \\
\hline Age at onset & 16 & 43 & 39 & 38 & Infancy & 13 & Childhood & Infancy \\
\hline Mode of inheritance & Sporadic & $\mathrm{AD}$ & $\mathrm{AD}$ & $\mathrm{AD}$ & Sporadic & $\mathrm{AD}$ & $\mathrm{AR}$ & $\mathrm{AD}$ s/o \\
\hline $\begin{array}{l}\text { Muscle atrophy } \\
\text { Respiratory failure }\end{array}$ & $\begin{array}{l}\text { Proxymal } \\
(+)\end{array}$ & $\begin{array}{c}\text { Distal } \\
(+)\end{array}$ & $\begin{array}{c}\text { Distal } \\
(+)\end{array}$ & $\begin{array}{c}\text { Distal } \\
(+)\end{array}$ & $\begin{array}{l}\text { Diffuse } \\
(-)\end{array}$ & $\begin{array}{l}\text { Proxymal } \\
(+)\end{array}$ & $\begin{array}{l}\text { Proxymal } \\
(+)\end{array}$ & $\begin{array}{c}\text { Diffuse } \\
(+)\end{array}$ \\
\hline Contraction of joints & $(+)$ & $(-)$ & $(-)$ & $(-)$ & $(-)$ & $(-)$ & $(+)$ & $(+)$ \\
\hline Scoliosis & $(-)$ & $(-)$ & $(-)$ & $(-)$ & $(-)$ & $(+)$ & $(-)$ & $(+)$ \\
\hline \multicolumn{9}{|l|}{ Abnormality of } \\
\hline UCG & 1 & I & 1 & 1 & 1 & $(+)$ & $(+)$ & $(+)$ \\
\hline catheterization & l & / & / & / & 1 & 1 & 1 & $(+)$ \\
\hline histology of myocardium & / & / & l & I & / & I & I & $(+)$ \\
\hline $\begin{array}{l}\text { Serum CK } \\
\text { Prognosis } \\
\text { Autopsy }\end{array}$ & $\begin{array}{c}\text { Normal } \\
\text { Poor } \\
(+)\end{array}$ & $\begin{array}{c}\text { Elevated } \\
\text { Poor } \\
(-)\end{array}$ & $\begin{array}{c}\text { Elevated } \\
\text { Poor } \\
(-)\end{array}$ & $\begin{array}{c}\text { Elevated } \\
\text { Poor } \\
(-)\end{array}$ & $\begin{array}{l}\text { Normal } \\
\text { Poor } \\
(-)\end{array}$ & $\begin{array}{c}\text { Elevated } \\
\text { Poor } \\
(-)\end{array}$ & $\begin{array}{c}/ \\
\text { Poor } \\
(-)\end{array}$ & $\begin{array}{c}\text { Elevated } \\
\text { Poor } \\
(+)\end{array}$ \\
\hline
\end{tabular}

AD: autosomal dominant trait, AR: autosomal recessive trait,/: not recorded, ECG: electrocardiogram, UCG: ultrasonic cardiography. 


\section{SEKIJIMA et al}

was not clearly demonstrated that the cytoplasmic bodies originated from Z-line. However, cytoplasmic bodies and HCM can be related to the Z-line structure and some Z-line components, such as $\alpha$-actinin (30) and desmin which are expressed both in skeletal and cardiac muscles. Thus, the abnormality of the Z-line component might be responsible for Z-line-related cytoplasmic bodies and HCM.

Acknowledgement: We would like to thank Dr. Ikuya Nonaka (National Institute of Neuroscience, NCNP, Tokyo, Japan) for his valuable comments on muscle histology.

\section{References}

1) Nakashima $\mathrm{N}$, Tamura $\mathrm{Z}$, Okamoto $\mathrm{S}$, et al. Inclusion bodies in human neuromuscular disorder. Arch Neurol 22: 270, 1970.

2) Kinoshita M, Satoyoshi E, Suzuki Y. Atypical myopathy with myofibrillar aggregates. Arch Neurol 32: 417, 1975.

3) Clark JR, d'Agostino AN, Wilson J, et al. Autosomal dominant myofibrillar inclusion body myopathy: clinical, histologic, histochemical, and ultrastructural characteristics. Neurology (Minneap) 28: 399, 1978 (abstract).

4) Jerusalem F, Ludin H, Bischoff A, et al. Cytoplasmic body neuromyopathy presenting as respiratory failure and weight loss. J Neurol Sci 41: 1, 1979.

5) Edström L, Thornell LE, Eriksson A. A new type of hereditary distal myopathy with characteristic sarcoplasmic bodies and intermediate (skeletin) filaments. J Neurol Sci 47: 171, 1980.

6) Goebel HH, Schloon H, Lenard HG. Congenital myopathy with cytoplasmic bodies. Neuropediatrics 12: 166, 1981.

7) Wolburg H, Schlote W, Langohr HD, et al. Slowly progressive congenital myopathy with cytoplasmic bodies. Report of two cases and a review of the literature. Clin Neuropathol 1: 55, 1982.

8) Patel H, Berry K, MacLeod P, Dunn HG. Cytoplasmic body myopathy. Report on a family and review of the literature. J Neurol Sci 60: 281, 1983.

9) Otsuji Y, Osame M, Tei C, et al. Cardiac involvement in congenital myopathy. Int J Cardiol 9: 311, 1985.

10) Dickoff DJ, Hays AP, Uncini A, et al. Autosomal dominant cytoplasmic body myopathy. Ann Neurol 22: 124, 1987 (abstract).

11) Mizuno $Y$, Nakamura $Y$, Komiya $K$. The spectrum of cytoplasmic body myopathy: report of a congenital severe case. Brain Dev 11: 20, 1989.

12) Chapon F, Viader F, Fardeau M, et al. Hereditary myopathy with cytoplasmic (spheroid) bodies revealed by respiratory failure. Rev Neurol (Paris) 145: 460, 1989.

13) Bertini E, Ricci E, Boldrini R, et al. Involvement of respiratory muscles in cytoplasmic body myopathy. A pathological study. Brain Dev 12: 798, 1990.

14) Schröder JM, Sommer C, Schmidt B. Desmin and actin associated with cytoplasmic bodies in skeletal muscle fibers: immunocytochemical and fine structural studies, with a note on unusual 18 - to 20-nm filaments. Acta
Neuropathol (Berl) 80: 406, 1990.

15) Arahata $\mathrm{K}$, Beggs $\mathrm{AH}$, Honda $\mathrm{H}$, et al. Preservation of the $\mathrm{C}$-terminus of dystrophin molecule in the skeletal muscle from Becker muscular dystrophy. J Neurol Sci 101: 148, 1991.

16) Engel WK. The essentiality of histo- and cytochemical studies of skeletal muscle in the investigation of neuromuscular disease. Neurology 12: 778, 1962.

17) MacDonald RD, Engel AG. The cytoplasmic body: another structural anomaly of the Z disk. Acta Neuropathol 14: 99, 1969.

18) Chou SM, Mizuno Y. Induction of spheroid cytoplasmic bodies in a rat muscle by local tetanus. Muscle Nerve 9: 455, 1986.

19) Osborne M, Goebel HH. The cytoplasmic bodies in a congenital myopathy can be stained with antibodies to desmin, the muscle-specific intermediate filament protein. Acta Neuropathol (Berl) 62: 149, 1983.

20) Solomon SD, Geisterfer-Lowrance ATT, Vosberg HP, et al. A locus for familial hypertrophic cardiomyopathy is closely linked to the cardiac myosin heavy chain genes, CRI-L436, and CRI-L329 on chromosome 14 at q11-q12. Am J Hum Genet 47: 389, 1990.

21) Tanigawa G, Jarcho JA, Kass $S$, et al. A molecular basis for familial hypertrophic cardiomyopathy: an $\alpha / B$ cardiac myosin heavy chain hybrid gene. Cell 62: 991, 1990.

22) Thierfelder L, MacRae C, Watkins H, et al. A familial hypertrophic cardiomyopathy locus maps to chromosome 15q2. Proc Natl Acad Sci USA 90: $6270,1993$.

23) Watkins $H$, MacRae $C$, Thierfelder $L$, et al. A disease locus for familial hypertrophic cardiomyopathy maps to chromosome 1q3. Nature Genet 3: 333, 1993

24) Thierfelder $\mathrm{L}$, Watkins $\mathrm{H}$, MacRae $\mathrm{C}$, et al. $\alpha$-Tropomyosin and cardiac troponin $\mathrm{T}$ mutations cause familial hypertrophic cardiomyopathy: a disease of the sarcomere. Cell 77: 701, 1994.

25) Carrier L, Hengstenberg C, Beckmann JS, et al. Mapping of a novel gene for familial hypertrophic cardiomyopathy to chromosome 11. Nature Genet 4: 311, 1993.

26) Nishi H, Kimura A, Sasaki M, et al. Localization of the gene for hypertrophic cardiomyopathy to chromosome 18q. Circulation $\mathbf{8 0}$ (suppl II): II-457, 1989 (abstract).

27) Ambrosini M, Ferraro M, Reale A. Cytogenetic study in familial hypertrophic cardiomyopathy: identification of a new fragile site on human chromosome 16. Circulation 80 (suppl II): II-458, 1989 (abstract).

28) Epstein N, Fananapazir L, Lin H, et al. Genetic heterogeneity in hypertrophic cardiomyopathy: evidence that HCM maps to chromosome $2 \mathrm{q}$ Circulation 82 (suppl III): III-399, 1990 (abstract).

29) Schultheiss $T$, Choi J, Lin ZX, et al. A sarcomeric $\alpha$-actinin truncated at the carboxyl end induces the breakdown of stress fibers in PtK2 cells and the formation of nemaline-like bodies and breakdown of myofibrils in myotubes. Proc Natl Acad Sci USA 89: 9282, 1992.

30) Beggs AH, Byers TJ, Knoll JHM, et al. Cloning and characterization of two human skeletal muscle $\alpha$-actinin genes located on chromosomes 1 and 11. J Bio Chem 267: 9281, 1992. 